\title{
Analysis on Design of Urban Wetland Landscape Park
}

\author{
Kun Xie \\ Eastern International Art College \\ Zhengzhou University of Light Industry \\ Zhengzhou, Henan, China 451450
}

\begin{abstract}
The design of urban wetland landscape parks is to comprehensively strengthen urban wetland protection, maintain ecological characteristics and basic function of urban wetlands ecosystem and give play to the role of urban wetland in improving urban ecological environment, beautifying city, scientific research, science popularization education and leisure amusement. This article discusses relevant contents of its design, aims at effectively containing the phenomenon of irrational utilization for wetland in urban construction, ensuring sustainable utilization of wetland resource and realizing harmonious development of human and nature.
\end{abstract}

Keywords-wetland; urban wetland landscape parks; ecological

\section{INTRODUCTION}

The design of wetland landscape is an important constituent part of environmental art design. The design of urban wetland landscape design can tease chaotic living environment, make people in it feel the comfortable environment and give people good spiritual enjoyment. Meanwhile, it also has the propaganda function to protect wetlands. In narrow sense, the concept of wetland is generally considered as transitional zone between land and water area. In broad sense, it is defined as the regions including swamps, mud flats, neritic regions where the depth of water doesn't exceed six meters, rivers, lakes, reservoirs and rice fields, etc. In design of urban wetland landscape art design, reasonable combination of vast green planting and water landscape and proper setting of facility can create a healthy, comfortable living environment with natural ecological virtuous circle that has long-term development potential. The design of urban wetland landscape can make people who live in blatant cities close to nature. It is the bridge to connect city and nature. It can provide places for cities to back to nature, meet diversified living demands of people in modern life and make living space of people bro.

Since May 2013, the Wetland Protection Management Regulations formulated by State Forestry Bureau was implemented formally. It is obvious that people pay more and more attention to wetlands. The environment of wetland landscape can improve surrounding climatic environment, protect and regulate the ecological system within certain range. For example, a large area of water area and vegetation environment appeared in wetlands can collect dust, reduce noise and adjust environment humidity. They improve the environment from many aspects and promote the degree of comfort of the environment. Wetlands play an important role in protecting diversity of species. The symbiosis of many species forms an ecological environment structure, provides resources for the production and living of human and forms powerful environmental function and benefits. Establishing natural reserve areas of various wetland types is one of the effective measures to protect wetlands ecosystem and wetland resources. We shall depend on protection zones and wetland parks of various wetland types, make full use of and excavate tourism resources of wetlands, vigorously develop ecological tourism and further promote wetland protection.

\section{THE FEATURES OF URBAN WETLAND LANDSCAPE PARK}

Wetland parks are important constituent parts of national wetland protection system. Together with wetland nature reserve, specific conservation region, habitat to protect wetland fauna and flora, wetland multi-purpose management area, it forms wetland protection management system. Developing and constructing wetland parks is a specific measure to implement protection and management strategy of hierarchical classification of national wetlands and also one of the effective ways to maintain and enlarge protection area of wetlands under the current situation. Developing and constructing wetland parks can help to mobilize social forces to participate in the protection and sustainable utilization of wetlands, give full play to a variety of functional benefits of wetlands and meet requirements of the public and social and economic development at the same time. Through participation of the society and scientific operating management, it can reach the target to protect wetlands ecosystem and maintain the continuous exertion of various benefits of wetlands. It is of great importance to improve regional ecological conditions, promote sustainable development of economy and society and realize harmonious coexistence of human and nature.

Urban wetland landscape parks are unique type of park. Meanwhile, it is also the representative of protection and design of urban wetland landscape. It refers to the park that is brought into urban green space system planning, has ecological functions and typical characteristics of wetlands and takes ecological protection, science popularization education, natural wilderness, leisure and tour as main contents. Urban 
wetland landscape parks have essential difference from other water landscape parks. Urban wetland landscape parks mainly protect the ecology in wetlands ecosystem and show its basic functions, pay attention to the publicity of science popularization education and inheritance of property of cultural value of wetlands. Different from other wetland nature reserves, urban wetland landscape parks use sight spaces in the city, popularize the knowledge to protect natural ecological environment and the cognition of diversity of species for people who tour in it, in order to promote greater social value and social property in the space of urban wetland landscape parks.

It is inappropriate to only regard urban wetland landscape parks as simple city parks that have tourism resources. We shall pay more attention to its sustainable development. It is necessary to base on conditions of urban wetland landscape parks, such as large area of water and greening, further exert its ecological function in the whole city and attach importance to planning of sustainable development of ecological system, let "kidney of the earth" better "eliminate toxin and clear away the lung-heat" for our home, in order to find the functions of wetland that disappear increasingly and ecological balance that is broken. In design of urban wetland landscape parks, when it continuously meets the requirements of users, its space also has relevant influence on visual sense, emotion, spirit and culture of people. The visual perception of design on people is the most important thing. A pleasant environment of urban wetland landscape parks can bring people good enjoyment visually and let people are willing to enter it to feel the diversification of the space. Meanwhile, in a space environment that can attract people to stay, designers need to make users have spiritual and emotional resonance and find the continuation of development of wetland culture in the park. The environment stimulates people through mobilizing internal motivation of people and exerting creative potential of people to produce active behaviors. It can strengthen self-confidence of people, show self-value to get the recognition of society. Ideal environment can enlighten the spirit.

\section{The Planning TARget of URBAN WetLAND LANDSCAPE PARK}

The planning of urban wetland landscape parks regards natural renaissance of wetlands and recovery of territory of wetlands as the guiding thoughts. It is necessary to form the space that gathers various natural spaces and diversified communities of animal and plant species, strengthens integrality and provide a natural and peaceful, exuberant and comprehensive space type. In the whole urban wetland landscape parks, the design of water area of wetlands and surrounding lands is the key point of the whole planning. The primary task is about how to recover natural and ecological systematization of the whole wetlands. Secondly, it is about how to continue promoting the development of ecological system of wetlands, strengthen and promote diversification of each species and realize naturalization of urban wetland landscape parks. It is the core mission to improve the whole quality of soil and water body in wetland environment and coordinate relationship between water and plants.
The general objective for planning and design of urban wetland landscape parks is to reduce disturbance and destruction of urban development on wetland environment, improve natural productivity of wetlands and the surrounding environment. Through recovering the original natural ability of wetlands, make it have the ability of self-renewal, improve soil conditions of surrounding land, create conditions for the recovery of vegetation, thus to make urban wetlands have richer vitality. Meanwhile, in today's fast development of city, it is a problem that intensifies increasingly about how to keep the balance between all kinds of lands. It can also realize sustainable development of urban wetland environment to meet requirements of city people and establish urban wetland landscape parks with pleasant environment. Urban wetland landscape parks can also provide people with gathering place, entertainment venues, places for scientific research and education. It has functions in aesthetic aspects such as natural tourism, travel and recreation and huge landscape value. According to development of human nature, through the ages, wetland environment that has unique environmental advantages and resources superiority is always ideal place for people to live. At the same time, in civilization of development and progress of human society, wetlands are also one of the important cradles. The water body of urban wetland landscape parks also plays an important role in beautifying the environment and providing users with spaces of leisure and recreation. Abundant species in urban wetland landscape parks also have important social effects on scientific research, publicity and education. People can do scientific research on relevant genetic gene of wild fauna and flora and bring science popularization education through cognition of material objects. The information on the past and present evolution process in aspects such as biology and geography preserved by urban landscape wetland landscape parks has very important and unique values.

The planning objective of urban wetland landscape parks is about how to integrate the governance of wetlands with landscape planning. It is necessary to solve problems from many aspects. In initial stage of design, carry out careful and in-depth research work, set about from many aspects such as soil structure of different levels, underground water level and component materials of different layers, activity habits of animals and plants in relevant ecological system, changes and rules of all kinds of landscape elements, to do preparatory work for subsequent design from the outside to the inside. The concept of "water" is the theme of planning and design. Take urban wetland landscape parks as the ecological corridor to exchange biology and energy, integrate all kinds of ecological systems such as surrounding greenbelts, forest lands, farmlands, cities and villages to jointly form new landscape. Water ecological environment has close relationship with wetlands. Water is the link to connect wetland environment and hydrological and ecological systems. It is an important element to determine properties of wetlands as well as basic element in hydrological and ecological environment. Wetlands are important performance of hydrological and ecological environment. If there isn't good hydrological environment, it will not have healthy wetland environment, nor form urban wetland landscape parks with pleasant environment. The protection for wetlands is also important contents in protecting 
hydrological and ecological environment and also powerful measure to protect urban wetland environment. The damage to wetland environment will directly influence hydrological and ecological environment. The deterioration of hydrological and ecological environment will cause unhealthy development of wetlands. They supplement each other. Healthy wetland environment and good hydrological and ecological system are basic conditions for the survival of mankind and necessary basis of sustainable development of human. Reasonable planning and design of urban wetland landscape parks reflects basic protection and correct development of wetland environment and hydrological and ecological system. Planning of urban wetland landscape parks shall take various elements in the whole material cycle of wetlands, such as water body, farmland, soil, vegetation, animals, natural condition and ecological system as basic elements of planning and integrate them in the requirements to form complete territorial landscape planning. Especially various natural elements in the environment, no matter what their status is, natural or artificial, they should serve as the most important elements in the planning, in order to form frameworks of landscape type and landscape characteristic of urban wetland parks.

\section{The PlanNing REQUiREMENTS OF URBAN WETLAND LANDSCAPE PARK}

The planning of urban wetland landscape parks shall pay attention to the following requirements.

Firstly, one of the most important links of planning of urban wetland landscape parks is to realize natural circulation of water. It is necessary to improve the relation between surface water and underground water of wetlands to make them supplement each other. And then take necessary measures to improve the vitality of rivers that serve as water source of wetlands.

Secondly, another important link of planning of urban wetland landscape parks is to take proper way to form beneficial supplement of surface water for underground water, to make soil structure around wetlands change. The porosity and water content of soil increase to form diversified soil type.

Thirdly, planning of urban wetland landscape parks shall start from the overall perspective, adjust drainage and water diversion system in surrounding area to ensure reasonable and efficient use of water resources of wetlands. Where possible, it shall properly excavate new drainage system and adopt processing mode of penetrable water bottom, for the sake of balance of underground water level of the whole park.

Fourthly, as one of the elements of landscape planning, soil is formed by overlaying of different materials on soil profile. Different soil types produce different traces on earth's surface and landscape types. The planning of urban wetland landscape parks must base on scientific analysis and evaluation methods and use mature experience, materials and technology to find its ability of natural evolution.

Fifthly, soil structure plays an important role in the construction of urban wetland landscape parks. Because the content of nutrient in sandy soil is low, it is difficult for plants to grow. And it is easy to make water body rapidly permeate in underground. It is inappropriate to set it in the bottom layer. Clay minerals help to prevent water body from rapidly penetrating in the underground and can restrict the penetration of plant root system or rootstock. So we usually adopt clay to construct the bottom layer of wetlands. Soil can replace clay to be placed at the bottom layer. But we shall properly increase its thickness.

Sixthly, the ecological design of revetment of urban wetland landscape parks is of vital importance for construction of environment in shore of wetlands in boundary of land and water. It deserves careful consideration. The revetment constructed by concrete destroys the filtration and permeation effects of wetlands on surrounding environment. Because artificial lawn has weak self-adjustment ability, management measures such as irrigation, weeding and chemicals spraying easily lead to the fact that residual chemicals flow into water body to cause pollution.

\section{CONCLUSION}

The design of urban wetland landscape parks is to comprehensively strengthen the protection of urban wetlands, maintain ecological characteristics and basic functions of ecological system of urban wetlands and furthest exert the effect of urban wetlands in improvement of urban ecological environment, urban beautification, scientific research, science popularization education and leisure amusement. The ecological, environmental and social benefits of them will effectively contain the phenomenon of unreasonable use of wetlands in urban construction. Ensure sustainable use of wetland resources, realize harmonious development of human and nature, adhere to the principle of harmonious coexistence between human and wetlands, correctly treat and handle the relationships between human and nature, human and human. We should fully realize that protecting wetlands is to protect water ecological environment. Protecting wetlands is to protect ourselves. Protecting the environment is to protect the homeland that we live in.

\section{REFERENCES}

[1] Cheng Yuning. Wetland Park Design [M], Beijing: China Building Industry Press, 2012, 5.

[2] Lu Jianjian. Wetland Ecology [M], Beijing: Higher Education Press, 2006, 7.

[3] Cui Baoshan. Wetland Science [M], Beijing: Beijing Normal University Press, 2006, 12

[4] Dan Xinqiu, Wu Houjian. Theory and Practice of Wetland Park Construction [M], Beijing: Chinese Forestry Publishing House, 2009, 12

[5] Zhang Yujun, Liu Guoqiang. Planning Method of Wetland Park and Case Analysis [M], Beijing: China Building Industry Press, 2013, 1. 